\title{
ALTERNATIF PEMILIHAN LOKASI BANDARA DOMESTIK DI KABUPATEN LAMONGAN
}

\author{
Gadik Cahyanto $^{[1]}$, Zulkifli Lubis ${ }^{[2]}$ \\ ${ }^{1]}$ Program Studi Teknik Sipil Fakultas Teknik Universitas Islam Lamongan \\ ${ }^{2]}$ Fakultas Teknik Universitas Islam Lamongan \\ email :gaaadik@gmail.com, cheppy.lubis@gmail.com
}

\begin{abstract}
Lamongan regency is a regency in East Java province and enter the strategic area of development of Kertasusila Gate, Juanda Airport development discourse began to be raised to the surface. Was triggered by a prediction in 2019 which mentions Juanda International Airport experiencing passenger and flight density, coinciding with AFTA in 2015 which is an ASEAN Open Sky program held in ASEAN. East Java Provincial Government puts the plan into East Java Provincial RTRW 2011-2031. The airport development in Lamongan Regency has also been included in the document of East Java Province Transportation (Tatrawil) in 2012-2032. Therefore it is necessary to determine the location of the airport in Lamongan Regency. This Research In accordance with KM No. 20 Year 2014 Minister of Transportation on the procedures and procedures for determining the location of the airport then the feasibility of determining the location of the new airport is based on 2 aspects of feasibility in use to confirm the variables that affect the determination of alternative locations in Lamongan regency namely the administrative and technical aspects. Based on multi-criteria analysis then selected alternative location in Paciran village South axis on the left side of the direction from Gresik City to Tuban. Based on analysis and observation overlay obtained airport matching location is in Paciran district with coordinates 6 $6^{\circ} 3^{\prime} 09.13$ "S, $112^{\circ} 22^{\prime} 19.31$ "T (Elevation $7 m$, eye height $5.75 \mathrm{~km}$ ).
\end{abstract}

Keywords: Airport, Lamongan, Location Determination, Scoring Analysis

\section{PENDAhUluan}

Wacana pengembangan Bandara Juanda mulai diangkat kepermukaan. Hal itu dipicu prediksi pada 2019 yang menyebutkan Bandara Internasional Juanda mengalami kepadatan penumpang dan penerbangan. Jumlah penumpang setiap tahun meningkat hingga mencapai sekitar 15,3 juta orang. Padahal, kapasitas terminal hanya 6,5 juta penumpang per tahun. Saking padatnya, jarak kedatangan dan keberangkatan pesawat saat jam sibuk mencapai 1,20 menit. Untuk mengatasi hal tersebut, PT Angkasa Pura I membangun terminal 2 dengan kapasitas 6 juta penumpang per tahun. Ada pula rencana pembangunan terminal 3 dengan kapasitas 17 juta penumpang serta ditambah runway baru (Kepala Bappeprov Jatim Fattah Jasin).

Kawasan strategis pengembangan Gerbang kertasusila jawa Timur, Kota Surabaya yang menjadi pusat pertumbuhan dilayani oleh
Bandar udara Internasional Juanda. Sebagai gerbang utama pada jalur udara Bandar udara Internasional Juanda selalu mengalami kenaikan jumlah penerbangan dalam melakukan pelayanan. Akan tetapi dampak dari adanya kegiatan bandar udara ini masih belum bisa dimaksimalkan oleh daerah lain selain Kota Surabaya di Wilayah Provinsi Jawa Timur.

Diberlakukanya AFTA pada tahun 2015, program ASEAN Open Sky yang diselenggarakan di langit ASEAN merupakan suatu program yang memberikan maskapai penerbangan flexibilitas dan kapasitas dalam mengembangkan rute penerbangan. Dalam menghadapai program AFTA dan ASEAN Open Sky yaitu dengan cara memperbesar kapasitas bandara atau membangun bandara baru. Pemerintah Provinsi Jawa Timur sendiri sudah memikirkan hal tersebut dengan menuangkan rencana dalam RTRW Provinsi Jawa Timur 2011-2031. Di dalam rencana 
tersebut dituliskan bahwa terdapat rencana pembangunan bandara di Kabupaten Lamongan. Selain pada RTRW, pembangunan bandara di Kabupaten Lamongan juga telah dimasukkan kedalam dokumen Tataran Transportasi Wilayah Provinsi Jawa Timur (Tatrawil) tahun 2012-2032 yang sudah di Perda-kan. Pada salah satu pasalnya disebutkan bahwa adanya pengembangan bandara internasional di kawasan Pantura Jawa Timur untuk mendukung percepatan pertumbuhan KPI-Lamongan dan KPIGresik,.

Wilayah yang mempunyai bandar udara akan sangat mendukung pada perkembangannya. Selain itu rencana pengembangan bandar udara baru di Kabupaten Lamongan dalam RTRW Jatim belum ditentukan lokasinya sehingga perlu diadakan penelitian lokasi bandar udara di Kabupaten Lamongan. Tujuan penelitian ini adalah melakukan analisa karakteristik daerah rencana dan tipe yang akan di gunakan sebagai lokasi alternatif bandara di kabupaten Lamongan.

\section{METODE PENELITIAN}

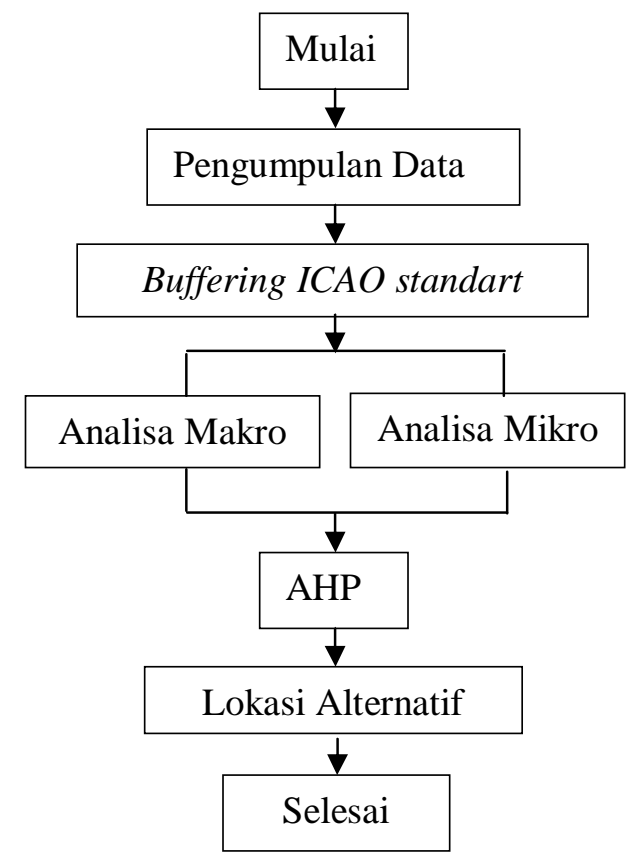

Gambar 1. Flow Chart Diagram Alir Penelitian

\section{A. Dasar Pemilihan Lokasi}

Sesuai dengan KM No. 20 Tahun 2014 Menteri Perhubungan tentang tata cara dan prosedur penetapan lokasi bandar udara maka kelayakan penetapan lokasi baru bandar udara didasarkan pada 2 aspek kelayakan, yaitu:

1. Kelayakan Administrasi

2. Kelayakan Teknis, yang terdiri dari:
a. Kelayakan pengembangan wilayah
b. Kelayakan ekonomi dan finansial
c. Kelayakan teknis pembangunan
d. Kelayakan operasional
e. Kelayakan angkutan udara
f. Kelayakan lingkungan

Lokasi-lokasi alternatif yang diajukan menjadi bandar udara di Kabupaten Lamongan terdapat 27 lokasi. Alternatif didapat berdasarkan jumlah kecamatan yang ada di Lamongan.

Tabel 1. Pembobotan Makro

\begin{aligned} \hline No & \multicolumn{1}{c}{ Kriteria } \\ \hline 1 & Tata Ruang \\ & a. Kesesuaian dengan RTRW Kota \\ & Kabupaten Lamongan \\ & b. Daya dukung Lahan Sekitar \\ & c. Potensi Pengembangan Wilayah \\ & dan pertumbuhan ekonomi \\ & d. Mendekati wilayah rencana \\ & kawasan potensial \end{aligned}

2 Transportasi

a. Dukungan perbaikan jaringan trayek

b. Dukungan terhadap perbaikan kinerja jaringan jalan

c. Kesesuaian dengan rencana pengembangan jaringan jalan

3 DampakterhadapSosial-Budaya

4 DampakLalulintas

5 TeknikKonstruksi
a. Luas Lahan
b. Kemudahan Pelaksanaan
c. Kemudahan bahan dan peralatan
d. Ketergantungan pihak lain
e. Biaya konstruksi

6 Ekonomi dan Finansial
a. Pengorbanan Penumpang (User dan nonuser costs)
b. Pengorbanan Operator (BOK)
c. Biaya Investasi
d. Minat Investor 
Tabel 2. Pembobotan Mikro

\begin{tabular}{cl}
\hline No & \multicolumn{1}{c}{ Kriteria } \\
\hline 1 & Kondisi luas daratan dan kontur \\
\hline 2 & Kestabilan tanah dasar \\
\hline 3 & Kemudahan dalam pembangunan \\
\hline 4 & Kedekatan dengan akses jalan \\
\hline 5 & Kesesuaian dengan RTRW \\
\hline 6 & $\begin{array}{l}\text { Kedekatan dengan jaringan jalan } \\
\text { eksisting }\end{array}$ \\
\hline 7 & Pola tata guna lahan di lokasi \\
\hline 8 & Kondisi hidrologi \\
\hline
\end{tabular}

\section{HASIL DAN PEMBAHASAN}

\section{A.Pembobotan Kriteria dan Variabel yang berpengaruh dalam penentuan lokasi Bandar Udara}

Pada tahap pertama ini akan dilakukan analisa pembobotan untuk mendapatkan kriteria dan variabel yang berpengaruh terhadap lokasi alternatif.

Pemberian Bobot dan Nilai

Setiap kriteria dari penilaian kelayakan memiliki bobot penilaian masing- masing.
Pemberian bobot dilakukan dengan 2 macam skenario, yaitu dengan menitik beratkan pada aspek ekonomis dan pada aspek pengembangan bandar udara. Untuk kedua skenario, pemberian bobot terhadap aspek lingkungan dan aspek teknik tetap mendapatkan bobot yang sama.

Tabel 3. Hasil Pembobotan Makro

\begin{tabular}{llc}
\hline No & Kecamatan & Bobot Area \\
\hline 1 & Brondong & 118 \\
\hline 2 & Glagah & 116 \\
\hline 3 & Kedungpring & 109 \\
\hline 4 & Kembangbahu & 129 \\
\hline 5 & Mantup & 127 \\
\hline 6 & Paciran & 145 \\
\hline 7 & Solokuro & 131 \\
\hline 8 & Sukodadi & 129 \\
\hline 9 & Turi & 113 \\
\hline & Jumlah & 1117
\end{tabular}

Sumber : Hasil Analisa

Tabel 4. Hasil Pembobotan Mikro

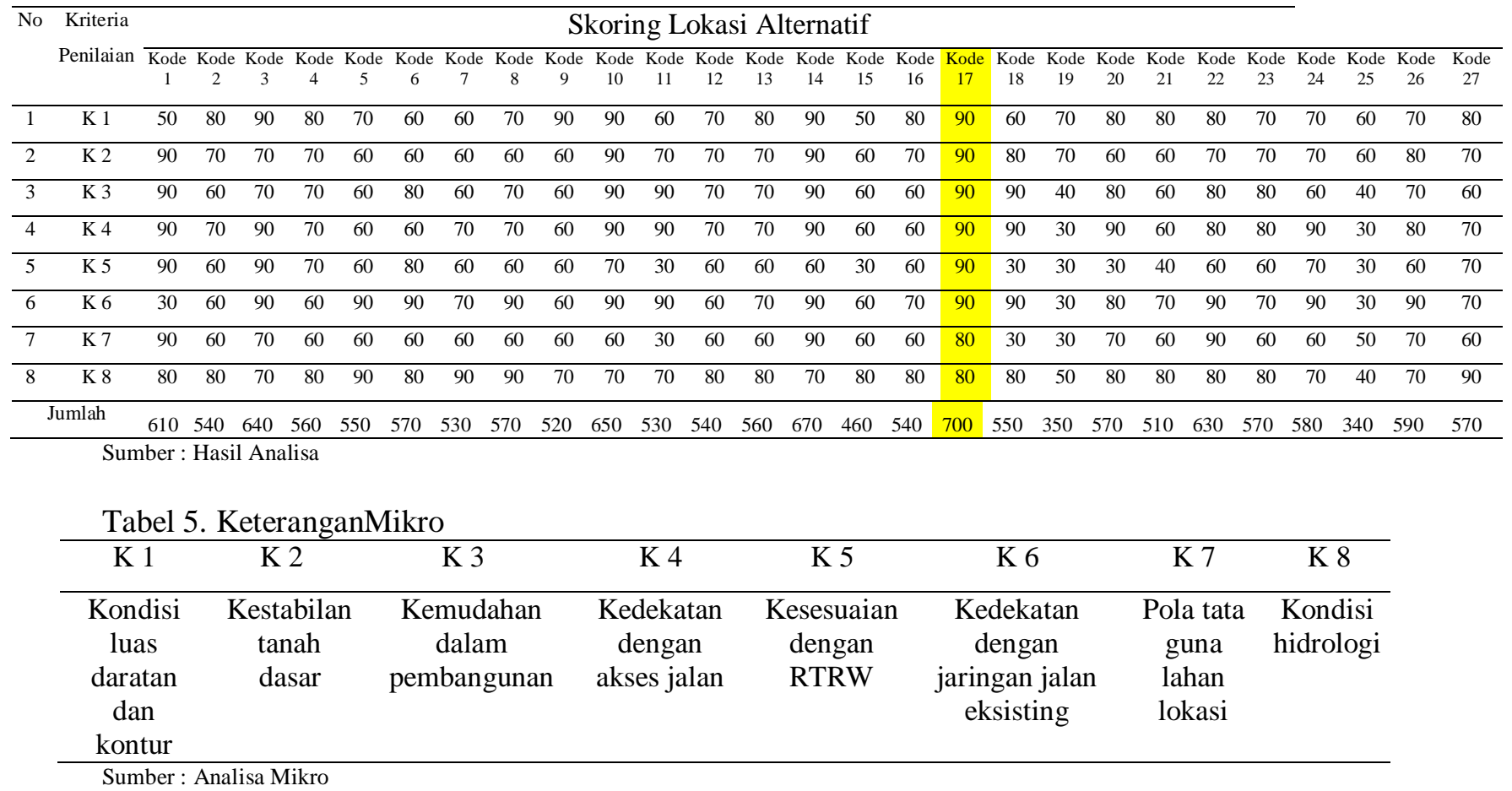


Tabel 6. Keterangan Mikro

\begin{tabular}{|c|c|}
\hline Kode & Kecamatan \\
\hline Kode 1 & Babat \\
\hline Kode 2 & Bluluk \\
\hline Kode 3 & Brondong \\
\hline Kode 4 & Deket \\
\hline Kode 5 & Glagah \\
\hline Kode 6 & Kalitengah \\
\hline Kode 7 & Karangbinangun \\
\hline Kode 8 & Karanggeneng \\
\hline Kode 9 & Kedungpring \\
\hline Kode 10 & Kembangbahu \\
\hline Kode 11 & Lamongankota \\
\hline Kode 12 & Laren \\
\hline Kode 13 & Maduran \\
\hline Kode 14 & Mantup \\
\hline Kode 15 & Modo \\
\hline Kode 16 & Ngimbang \\
\hline Kode 17 & Paciran \\
\hline Kode 18 & Pucuk \\
\hline Kode 19 & Sambeng \\
\hline Kode 20 & Sari rejo \\
\hline Kode 21 & Sekaran \\
\hline Kode 22 & Solokuro \\
\hline Kode 23 & Sugio \\
\hline Kode 24 & Sukodadi \\
\hline Kode 25 & Sukorame \\
\hline Kode 26 & Tikung \\
\hline Kode 27 & Turi \\
\hline
\end{tabular}

\section{B. PenentuanTipe (Kelas) Bandara}

ICAO memberikan tanda kode A, B, C, D dan $\mathrm{E}$ dalam mengklasifikasi Bandar Udara.
Dasar dari pembagian kelas - kelas adalah berdasarkan panjang landas pacunya saja, tidak berdasarkan fungsi dari Bandar udara, dan panjang landasan itu dasar ketinggian adalah sea level dan kondisi cuaca adalah standar atau $59^{\circ} \mathrm{F}$.

Tabel 7. Standart $I C A O$

\begin{tabular}{ccc}
\hline $\begin{array}{c}\text { Kelas } \\
\text { Bandara }\end{array}$ & Nilai & $\begin{array}{c}\text { Tingkat } \\
\text { Kesesuaian }\end{array}$ \\
\hline I & $>1800$ & $\begin{array}{c}\text { Sangat sesuai untuk } \\
\text { lokasi Bandara baru }\end{array}$ \\
\hline II & $\begin{array}{c}700- \\
800\end{array}$ & $\begin{array}{c}\text { Sesuai untuk lokasi } \\
\text { Bandara baru }\end{array}$ \\
\hline III & $<234$ & $\begin{array}{c}\text { Tidak sesuai untuk } \\
\text { lokasi Bandara baru }\end{array}$ \\
\hline
\end{tabular}

Sumber:ICAO

\section{Penentuan lokasi Bandar Udara di Kabupaten Lamongan}

Untuk mendapatkan lokasi alternatif bandar udara di Kabupaten Lamongan menggunakan metode weighted overlay. Analisis ini digunakan untuk menggabungkan peta-peta tematis yang sesuai dengan variabel kemudian di AHP. Berdasarkan hasil analisa didapat lokasi kesesuaian Bandar udara berada di antara Kecamatan Paciran dengan koordinat 6 53'09.13'S, $112^{\circ}$ 22' 19.31'T (Elevasi 7m , ketinggian mata $5.75 \mathrm{~km}$ ).

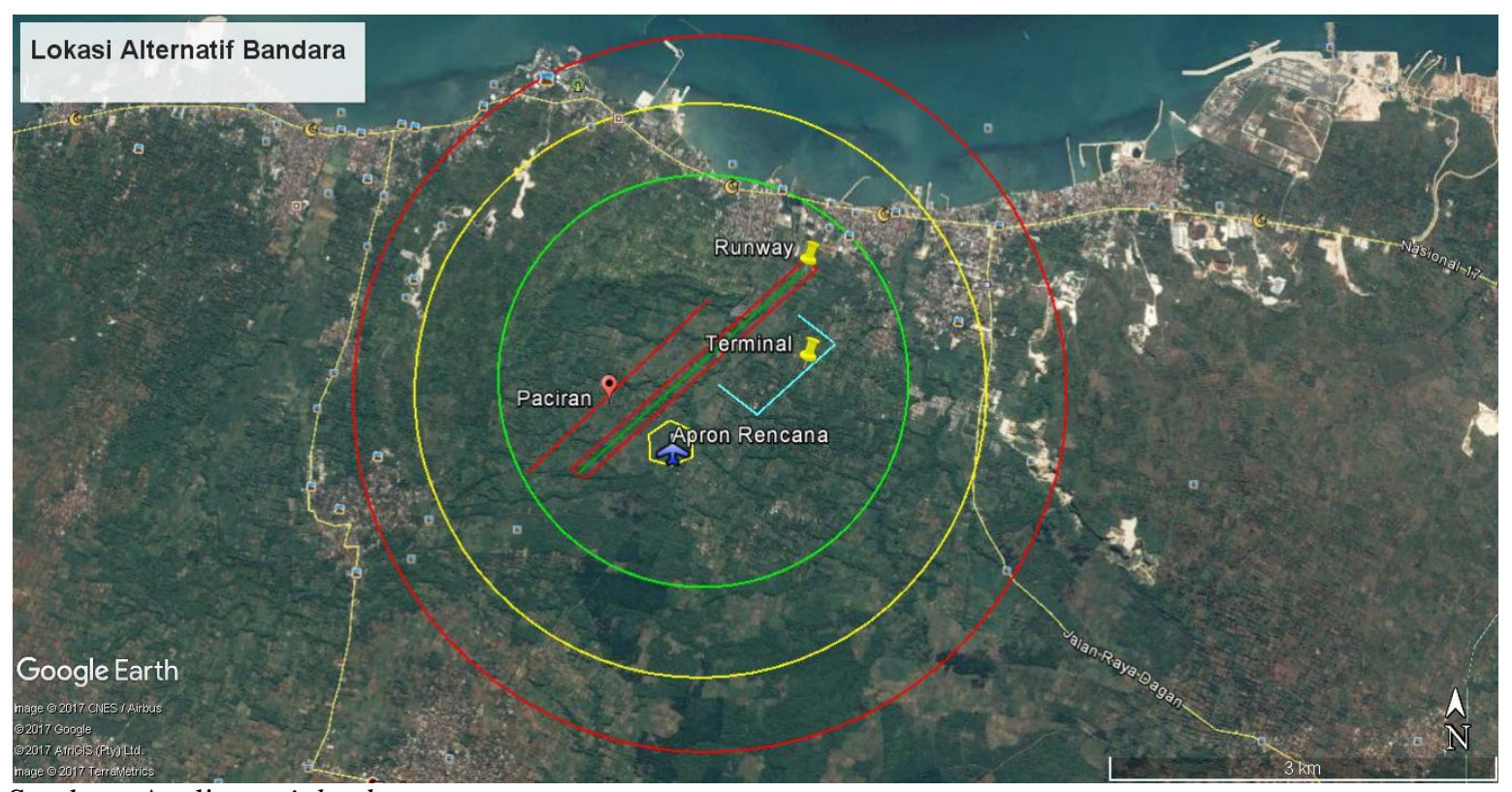

Sumber : Analisa weighted

Gambar 2. Lokasi Alternatif 


\section{KESIMPULAN}

Berdasarkan hasil analisa dan pembahasan dari beberapa lokasi alternatif pembangunan bandara domestik di kabupaten lamongan sebagai antisipasi lonjakan penumpang di bandara juanda diperoleh hasil kesimpulan sebagai berikut :

1. Karakteristik daerah rencana yang cocok untuk alternatif mempunyai Kesesuaian Kondisi luas daratan dan kontur, Kestabilan tanah dasar, Kemudahan dalam pembangunan, Kedekatan dengan akses jalan, Kesesuaian dengan RTRW, Kedekatan dengan jaringan jalan eksisting, Pola tata guna lahan dilokasi, Kondisi hidrologi.

2. Sesuai dengan Rencana Tata Ruang Provinsi Jawa Timur dan Kabupaten Lamongan bahwa Kota Lamongan sebagai salah pusat kegiatan nasional (PKN) perlu dilaksanakan suatu pembangunan Bandara.

3. Dari hasil kajian dengan tinjauan beberapa aspek sudut pandang teknis, aksebilitas dan dukungan lingkungan, lokasi yang terpilih untuk dijadikan Bandara Domestik di Kota Lamongan adalah di Seputar Paciran, di sekitar persawahan.

4. Berdasarkan analisis multi kriteria maka terpilihlah lokasi alternatif di desa Paciran Poros Selatan di tepi sebelah kiri arah dari Kota Gresik menuju Tuban.

5. Berdasarkan hasil analisa didapat lokasi kesesuaian Bandar udara berada di antara Kecamatan Paciran dengan koordinat $\quad 6^{\circ} 53^{\prime} 09.13^{\prime \prime} S, \quad 112^{\circ} \quad 22^{\prime}$ 19.31'T (Elevasi $7 \mathrm{~m}$, ketinggian mata $5.75 \mathrm{~km})$.

6. Berdasarkan analisis multi kriteria maka terpilihlah alternative desain bandara yang cocok untuk criteria daerah medan di kabupaten Lamongan adalah bandara Domestik Tipe B.

\section{DAFTAR PUSTAKA}

Aris Subagiyo,2015.Pemilihan Lokasi Bandar Udara Kabupaten Mahakam Ulu,Malang:Jurnal Tata Kota dan DaerahUniversitas Brawijaya,Volume 7, Nomor 2,
Basuki, Heru. Merancang, Merencana Lapangan Terbang. 1986. Alumni. Bandung.

CetakBiruDinasPerhubungan 2005

Horonjeff, Robert. 1993. "Planning and Design Of Airports" Fourth Edition. Mc.Grawhill.

ICAO(International Civil Aviation Organization). 19-23 October 2009. Forth Workshop/Meeting Of The SAM Implementation Group. Peru. Secretary General.

Kemeterian Perhubungan Republik Indonesia:

Keputusan Menteri Perhubungan nomor20 Tahun 2014 Menteri Perhubungantentang tatangan tata cara dan prosedurpenetapan lokasi bandar udara.

Rencana Tata RuangWilayah( RTRW) Lamongan Tahun 2016.

Ramadhan Tirta Saputra dan Sardjito.2016. Penentuan Lokasi Bandar Udara Di Kabupaten Lamongan, Surabaya: Jurnal Teknik ITS Vol. 5, No. 1.

StudiKelayakan\& SID Terminal KabupatenPulangPisau Kalimantan Tengah.

http://kabarlamonganjatim.blogspot.co.id/2016 /10/lamongan-akan-milikibandara.html(di akses09/08/2017 pkl:13:17)

http://www.republika.co.id/berita/nasional/daer $\mathrm{ah} / 15 / 02 / 26 / n k d 2 t 8$-perluasan-bandarajuanda-direncanakan-selesai-2019mendatang(di akses09/08/2017 pkl:13:31) 
Halaman ini sengaja dikosongkan 